\title{
Covid-19: Delays in getting tests are keeping doctors from work, health leaders warn
}

\section{Jacqui Thornton}

It is getting harder for hospital doctors to get covid-19 tests quickly for themselves, according to the Royal College of Physicians (RCP), amid concerns that NHS staff absences are being caused by a lack of access to testing.

A survey by the RCP of 898 of its members this week (22 September) asked if they had had a polymerase chain reaction test in the past two weeks. Of those who had, $80 \%$ were able to access testing within 24 hours, down from $88 \%$ in the previous survey in July. ${ }^{1}$

While absences from work are low-at $6.5 \%$ of those questioned $-40 \%$ of the doctors surveyed who are off work say it is because they are self-isolating while awaiting a test for someone in their household.

Andrew Goddard, president of the RCP, said testing remains an "enormous problem."' This is the RCP's sixth survey tracking the impact of the pandemic on the workforce. Goddard said, "We must ensure that rapid testing and results are available for health and social care staff or we'll end up tackling winter and the second wave with one hand tied behind our backs."

He added that the biggest problem is testing for doctors' household members. "Delays in accessing these tests mean that hundreds of doctors are having to self-isolate while they wait, and are unavailable to provide care. As the infection rate rises, the need for tests will rise, and a large proportion of the workforce could be out of action simply for want of a test."

Earlier this month a lack of covid-19 testing for doctors in secondary and primary care was being blamed for staff absences by NHS Providers, despite trusts claiming they have enough tests.

The latest figures from NHS Digital showed that more than one million days of work were lost in the NHS in England because of coronavirus related sickness between March and May. In May, 340900 full time equivalent days were lost, equating to $18.9 \%$ of all absences recorded. This is compared with $30.6 \%$ in April 2020 and 15.9\% in March 2020. ${ }^{2}$

NHS Providers chief executive Chris Hopson had said that unnamed trusts in Bristol, Leeds, and London had raised concerns about the lack of testing availability leading to greater levels of staff absence. ${ }^{3}$

And a survey of 750 doctors by lobby group Doctors Association UK (DAUK) revealed "hundreds" of doctors could not access tests. ${ }^{4}$ Three quarters who needed tests were not able to get them, which DAUK president Samantha Batt-Rawden called a “disgrace.”

It cited examples of a Gloucester GP who had to self-isolate for 6 days before a slot was available nearly 200 miles away in Norwich. Another doctor spoke of the only option being "an appointment in 90 minutes. It is a 419 mile journey to get there and takes seven hours."

The NHS Confederation, which represents organisations across the healthcare sector, said it was concerned. Director Layla McCay said that although health and care staff have priority access to testing, access problems and delays in receiving results mean that some may still have to self-isolate unnecessarily. ${ }^{5}$

She said that a lack of access to testing for staff was a major barrier to them delivering services and achieving targets set to restore services. "Some trusts are offering priority testing for the local NHS workforce but this is something which could be extended," she said.

The Royal College of GPs chair Martin Marshall said it was vital that GPs and their teams are prioritised for testing. "A lack of access to testing is already impacting on capacity in general practice, as staff isolate while awaiting results," he said. ${ }^{7}$

This week the college wrote to Dido Harding, head of the government's test-and-trace programme, warning that staff absences could hit the flu vaccination drive that ministers say is vital to stop the NHS becoming overwhelmed this winter. ${ }^{8}$

When asked to comment on tests for staff, the University Hospitals Bristol NHS Foundation Trust and Manchester University NHS Foundation Trust referred The BMJ to the Department of Health and Social Care. A spokesperson for Leeds Teaching Hospitals NHS Trust said they had enough tests and testing capacity themselves for staff.

A UCLH spokesperson said, "UCLH has a covid-19 staff testing service. As well as testing symptomatic staff, we also test household members with symptoms. The service has sufficient capacity to meet current demand."

The Department of Health and Social Care and NHS England did not respond to requests for comments. The department told the Guardian, "We test NHS staff, including GPs, with symptoms as a priority. We have the biggest testing system per head of population of all the major countries in Europe, which is processing tests at an unprecedented scale-more than 225000 a day on average over the past week."8

\footnotetext{
Royal College of Physicians. Covid-19 and workforce. September 2020. www.rcplondon.ac.uk/news/covid-19-and-workforce-ready-and-waiting.

2 NHS Digital. NHS sickness absence rates May 2020, provisional statistics. 24 September 2020. https://digital.nhs.uk/data-and-information/publications/statistical/nhs-sickness-absence-rates/may-2020-provisional.
} 
3 NHS Providers. NHS service recovery and winter preparation at risk from current testing shortages. 2020. https://nhsproviders.org/news-blogs/news/nhs-service-recovery-and-winter-preparationat-risk-from-current-testing-shortages.

4 Doctors Association UK. DAUK in Medscape: 3 in 4 doctors can't access testing. 17 September 2020. www.dauk.org/news/3-in-4-doctors-cant-access-testing.

5 NHS Confederation. We hope new app will help as test and trace not working well enough to keep public safe. September 2020. www.nhsconfed.org/news/2020/09/we-hope-new-app-willhelp-as-test-and-trace-not-working-well-enough-to-keep-public-safe.

6 NHS Confederation. Health leaders say lack of testing access is significant barrier to restoring services. 15 September 2020. www.nhsconfed.org/news/2020/09/lack-testing-access.

7 RCGP. General practice should not be a replacement for Test and Trace, says RCGP. September 2020. www.rcgp.org.uk/about-us/news/2020/september/general-practice-should-not-be-a-replacement-for-test-and-trace.aspx.

8 Campbell D. Lack of covid tests "forcing NHS GPs and nurses to stay off work." Guardian. 24 September 2020. www.theguardian.com/world/2020/sep/24/lack-of-covid-tests-forcing-nhsgps-and-nurses-to-stay-off-work. 